\section{Luis Înigo-Madrigal}

Fue Catedrático de Ciencia de la Literatura (1966-1973) y Profesor de Literatura Chilena Colonial y Moderna y de Literatura Hispanoamericana Colonial y Moderna en la Universidad de Chile y Catedrático de Teoría Literaria en la Universidad de Concepción (Chile) hasta 1973. Desde 1984 hasta el 2000 fue Catedrático de Literatura Hispanoamericana en la Universidad de Ginebra, Suiza, de la que es actualmente Professeur Honoraire. Ha enseñado además, entre otras, en las Universidades de Odense y Copenhague (Dinamarca), Leiden (Holanda), Neuchâtel (Suiza) y de La Laguna, Alcalá de Henares y Alicante (España). Autor de más de cien estudios sobre literatura hispanoamericana, ha editado la obra de numerosos autores, y proyectó y dirigió la Historia de la Literatura Hispanoamericana publicada por Cátedra (Madrid).

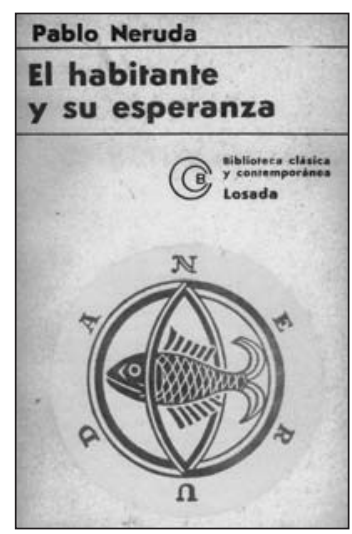

1

Pablo Neruda, El habitante y su esperanza. Novela, Santiago de Chile, Nascimento, 1926, 76 pp. El texto de esa primera edición (por la cual cito) «será reproducido sin modificaciones significativas en las posteriores», como indica Hernán Loyola en su edición de Pablo Neruda, Obras completas, I, Barcelona, Galaxia Gutenberg, 1999, pág. 1164; por más que, a mi juicio, contenga algunas erratas.

2

Escribo esta frase antes de conocer el libro de Hans Ulrich Gumbrecht, In 1926: Living at the Edge of Time, Harvard University Press, 1997, que, a pesar de su título, la confirma. Hay traducción española del libro de Gumbrecht: En 1926. Viviendo al borde del tiempo, México, Universidad Iberoamericana, 2004

El habitante y su esperanza y la novela de su época

LUIS ÍÑIGO-MADRIGAL

\title{
EL HABITANTE Y SU ESPERANZA Y LA NOVELA DE SU ÉPOCA
}

\author{
LUIS ÍNIIGO-MADRIGAL
}

La materia del mélico no tiene término prescripto, por que assí como el orador se espacia por toda materia con sus razones provables, traídas de lugares comunes, assí el lyrico trata qualquier materia que se le ofrezca.

Francisco Cascales, Tablas poéticas, Tabla Quinta

MatTRe De Philosophie: Sont-ce des vers que vous lui voulez écrire?

MONSIEUR JOURDAIN: Non, non, point de vers.

MaITRE DE PHILOSOPHIE: Vous ne voulez que de la prose?

MONSIEUR JOURDAIN: Non, je ne veux ni prose ni vers.

Mattre De Philosophie: Il faut bien que ce soit l'un, ou l'autre.

MOLIÈRE, Le bourgeois gentilhomme, Acte I, scène 5

Parte de la interminable bibliografía crítica sobre Neruda está recorrida, si se me permite parafrasear la frase de Borges sobre Whitman, por dos incesantes supersticiones: la primera supone que Neruda, el poeta, es un ejemplar único que no tiene pares ni antecesores en la literatura de su mundo; la segunda postula que toda la obra de Neruda, el hombre, forma parte de un proyecto cuyo fin y etapas están fijados, más o menos conscientemente, desde la adolescencia y que se cumple sin pasos en falso.

Las opiniones sobre la única novela de $\mathrm{Ne}-$ ruda, El habitante y su esperanza, publicada en $1926^{1}$, no siempre han eludido esas creencias. Esas opiniones son pocas, pero discordes: difieren sobre el género de la obra, sobre su argumento, sobre sus personajes. Y ninguna la inserta en la tradición que, aparentemente, le pertenece; esto es, la de la narrativa chilena -hispanoamericana- de las primeras décadas del siglo XX. Eso es lo que trataremos de hacer en los párrafos siguientes.

$$
* * *
$$

Mil novecientos veintiséis, como probablemente cualquier año del siglo pasado ${ }^{2}$, puede recordarse por la aparición de una serie de obras que forman parte aún de nuestras referencias literarias: es el año en que se publica por primera vez, cierto que de manera póstuma, El castillo, de Kafka; el año en que aparecen Al faro, de Virginia Wolf; El gran Gatsby, de F. Scott Fitzgerald, Fiesta, de Ernest Hemingway; El barco de la muerte de Bruno Traven; La paga de los soldados, la primera novela de William Faulkner. El año en que ven la luz Tirano Banderas, de Valle Inclán; Don Segundo Sombra, de Ricardo Güiraldes; El juguete rabioso, de Roberto Arlt.

En 1926 salen de prensa -sin contar las reediciones- veinticinco novelas de autores chi- 
lenos ${ }^{3}$; de las cuales de sólo cuatro, creo, se ha conservado memoria. De tres, me temo que exclusivamente en el restringido círculo de los especialistas en literatura chilena ${ }^{4}$; de la cuarta, El habitante y su esperanza, en círculos sin duda más amplios, aunque quizás no exclusivamente por su superioridad literaria sobre las demás.

Tras la aparente (y verdadera) diversidad de los títulos enumerados (que podrían ser muchísimos más) hay al menos un rasgo común: tienen tras de sí una tradición a la que pertenecen, y cuyas características -conocidas o no por sus autores- pueden acatar o subvertir. Esa tradición en el caso de las novelas hispanoamericanas -chilenas incluidas- es, señaladamente, la de la novela modernista en sus distintas manifestaciones (aunque también la de la novela universal a ellas contemporánea). Por ello quizá no esté fuera de lugar comenzar el examen de la novela de Neruda poniéndola en relación con una notable novela modernista.

$$
* * *
$$

En 1885, y por entregas, apareció en el neoyorquino periódico El Latino Americano la única novela de José Martí, Amistad funesta, que el cubano firmó con el pseudónimo de Adelaida Baralt. Años después Martí decidió publicar la obra en libro, ahora con el título de Lucía Jerez y con la adición de un prólogo, pero el proyecto no vería la luz hasta muchos años después, muerto ya su autor ${ }^{5}$. Nos interesa ahora ese prólogo; en él Martí comienza diciendo «Quien ha escrito esta noveluca, jamás había escrito otra antes... ni escribirá probablemente otra después»; para explicar a continuación que la ha compuesto por encar$\mathrm{go}^{6}$, que ha introducido en ella sus «propias observaciones y recuerdos», $y$, tras pedir excusas por sus «pecados», añade:

El autor... sabe bien por dónde va, profunda como un bisturí y útil como un médico, la novela moderna. El género no le place, sin embargo, porque hay mucho que fingir en él... Menos que todas, tienen derecho a la atención novelas como ésta, de puro cuento, en las que no es dado tender a nada serio, porque esto, a juicio de editores, aburre a la gente lectora...

Nadie, que yo sepa -pero mi ignorancia cubre vastos territorios-, ha puesto en relación el prólogo de Martí con el que, para su

también única novela, escribió Pablo Neruda. Este texto, a menudo citado como testimonio cuasi-biográfico, dice así:

He escrito este relato a petición de mi editor. No me interesa relatar cosa alguna. Para mí es labor dura, para todo el que tenga conciencia

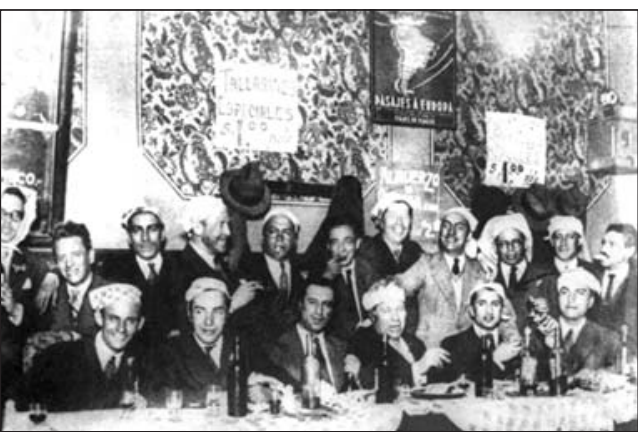

En el restaurante Hércules de Santiago en 1932.

de lo que es mejor, toda labor siempre es difíil. Yo tengo siempre predilecciones por las grandes ideas, y aunque la literatura se me ofrece con grandes vacilaciones y dudas, prefiero no hacer nada a escribir bailables o diversiones. [/] Yo tengo un concepto dramático de la vida, y romántico; no me corresponde lo que no llega profundamente a mi sensibilidad. [/] Para mífue muy difícil aliar esta constante de mi espiritu con una expresión más o menos propia. En mi segundo libro, Veinte poemas de amor y una canción desesperada, ya tuve algo de trabajo triunfante. Esta alegría de bastarse a sí mismo no la pueden conocer los equilibrados imbéciles que forman parte de nuestra vida literaria. [/] Como ciudadano,

3

Con algún posible error $\mathrm{u}$ omisión, y tomando «novela» en sentido lato, las siguientes: Antonio Acevedo Hernández, La hija de todos, Lectura Selecta № 19, 1926, 30 pp.; F. Alcocer Irigoyen, El oro negro. Escenas de la vida minera, Santiago de Chile, Imprenta Artes y Letras, 1926, 135 pp.; Pascual Brandi Vera, La fogata de los hampones, Santiago de Chile, Lectura Selecta, № 18, 1926, 25 pp.; Tilda Brito Letelier de Donoso [María Monvel, Leucone Grey, pseudónimos], El Marido gringo; El recuerdo fascinador, Santiago de Chile, Lectura Selecta, № 13, 1926 , 31 pp.; Marta Brunet, Bestia dañina, Santiago de Chile, Nascimento, 1926, 94 pp.; Armando Céspedes, El último decadente, Paris, Editions Le Livre Libre, 1926, 148 pp.; Ángel Cruchaga Santa María: Medianoche, Santiago de Chile, Lectura Selecta, $n^{\circ}$ 7, 1926, 31 pp.; Eduardo Garrido Merino, La estirpe, Santiago de Chile, Lectura Selecta, № 3, 1926, 36 pp.; Berta Lastarria Cavero, Escaramuzas mundanas, Santiago de Chile, Lecturas Selectas, № 20, 1926, 29 pp; Olga Lataste, Heroica,
Santiago de Chile, Imprenta Universitaria, 1926, 110 pp.; Armando Laurent, El cuento de abuelo, Santiago de Chile, Imprenta La Economía, 1926, 120 pp.; Juan Mackenna y Eyzaquigue, Flores pequeñas, San José de Costa Rica, Imprenta y Librería Alsina, 1926 , 275 pp.; Rafael Maluenda, De pluma y pelo, Santiago de Chile, Lectura Selecta, № 4, 1926 , 32 pp.; Ruperto Marchant Pereira, Dos meses de vacaciones. 11 de enero a 6 de marzo de 1781, Santiago de Chile, Imprenta Ramón Brias, 1926, 50 pp.; Augusto Millán Iriarte, Desarraigados, Novela de costumbres chilenas, Imprenta Bardi, 1926, 290 pp. ( $2^{\underline{a}}$ ed. en el mismo año); $\mathrm{Ar}$ mando Moock, Vida y milagros de un primer actor, Buenos Aires, Casa editorial Franco-lberoamericana, 1926, 255 pp.; Pablo Neruda, El habitante y su esperanza, Santiago de Chile, Nascimento, 1926, 76 pp.; Caupolicán Ponce, Las horas perdidas, Valparaíso, Imprenta Roma, 1926, 205 pp.; Jenaro Prieto, Un muerto de mal criterio, Santiago de Chile, Imprenta La Ilustración, 1926, 261 pp.; Salvador Reyes, El matador de tiburones, Santiago de Chile, Lectura Selecta, № 6, 1926, 31 pp.; Manuel Rojas, El hombre de los ojos azules, Santiago de Chile, Lectura Selecta, № 9, 1926, 35 pp.; Manuel Soto Morales, Marina, Santiago de Chile, Lectura Selecta, № 16, 1926, 32 pp.; Manuel Vásquez Órdenes, El sueño de una madre, Santiago de Chile, Imprenta El Comercio, 1926, 35 pp.; Nathanael Yáñez Silva, Aquella mujer extraña y pálida, Santiago de Chile, Lectura Selecta, № 18, 1926 44 pp.; ID., La tragedia del arte, Santiago de Chile, Nascimento, 1926, $192 \mathrm{pp}$.

\section{4}

Es el caso, creo, de Bestia dañina, de Marta Brunet; de Un muerto de mal criterio, de Jenaro Prieto; y de El hombre de los ojos azules, de Manuel Rojas.

5

Adelaida Ral [José Martí], "Amistad funesta», El Latino Americano, New York, mayoseptiembre 1885. Hay ahora una edición crítica de la novela que tiene en cuenta los manuscritos originales conservados en la Biblioteca Pública de Nueva York: José Martí, Lucía Jerez, edición crítica de Mauricio Núñez Rodríguez, La Habana, Letra negra - Centro de Estudios Martianos, 2001, $116 \mathrm{pp}$

6

«En la novela-agrega- había de haber mucho amor; alguna muerte; muchas muchachas, ninguna pasión pecaminosa; y nada que no fuese del mayor agrado de los padres de familia y de los señores sacerdotes. $Y$ había de ser hispanoamericana».

El habitante y su esperanz

y la novela de su época

LUIS ÍÑIGO-MADRIGAL 


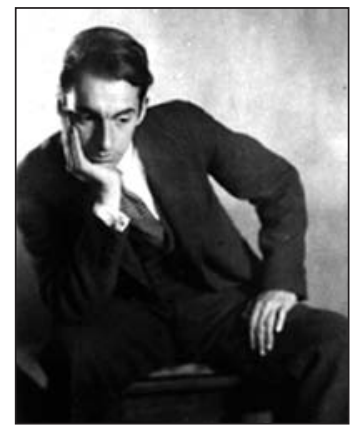

Neruda fotografiado por Georges Sauré.

7

El primero, Enrique Anderson Imbert, «La prosa poética de José Martí. A propósito de Amistad funesta", en sus Estudios sobre escritores de América, Buenos Aires, Raifal, 1954, pp. 125-165.

8

Luis Înigo-Madrigal, «Martí, novelista», en Homenaje al Dr. Rodolfo Oroz. Lengua, literatura, folklore, Santiago de Chile, Universidad de Chile, 1966, pp. 233-243.

9

Hernán Loyola, «El habitante y su esperanza, relato de vanguardia", Actas del Simposio Internacional de Estudios Hispánicos, Akademiai Klado, Budapest, 1976; tb. en Cuadernos para Investigación de la Literatura Hispánica, Madrid, 1980, núm. 2-3, pp. 213-222, por donde cito; p. 214.

\section{0}

Agreguemos que la novela epónima del «americanismo» chileno, Zurzulita, de Mariano Latorre (a quien Neruda profesaba cierta animadversión), se publica el mismo año que Alsino la novela poemática de Pedro Prado la quien Neruda profesaba amistad cierta), esto es, en 1920. Cfr. Pablo Neruda, "Mariano Latorre, Pedro Prado y mi propia sombra», en Pablo Neruda y Nicanor Parra, Discursos [de incorporación de Pablo Neruda a la Facultad de Filosofía y Educación de la Universidad de Chile, en calidad de Miembro Académico, y de recepción de Nicanor Parra], Santiago de Chile, Nascimento, 1962.

11

Raúl Silva Castro, «Una hora de charla con Pablo Neruda», El

El habitante y su esperanza y la novela de su época LUIS ÍNIIGO-MADRIGAL soy hombre tranquilo, enemigo de leyes, gobiernos e instituciones establecidas. Tengo repulsión por el burgués, y me gusta la vida de la gente intranquila e insatisfecha, sean éstos artistas o criminales.

Es más que probable que Neruda no conociese la novela de Martí (ni cualquier otra obra de Martí), por las fechas en que escribió El habitante..., pero entre el prólogo de su novela y la del cubano hay algunas coincidencias. Ambos declaran que han escrito la obra por encargo, ambos manifiestan que el género no les place, ambos dicen conocer las características de la novela de su tiempo.

Más: esas novelas menospreciadas por sus creadores han tenido una (buena) fortuna semejante. De Amistad funesta se ha dicho que es el inicio de la novela modernista ${ }^{7}$ (y aún de la novela naturalista ${ }^{8}$ ); de El habitante y su esperanza, que es la primera muestra de la novela vanguardista en Hispanoamérica.

$$
* * *
$$

Dejemos de lado la justeza de esas afirmaciones y volvamos a El habitante y su esperanza y su relación con la novela (hispanoamericana) de su época.

«No me interesa relatar cosa alguna... aunque la literatura se me ofrece con grandes vacilaciones y dudas, prefiero no hacer nada

Mercurio, Santiago de Chile, 10 de octubre de 1926; reproducido en Pablo Neruda, Obras completas, ed. cit., V, pp. 10471053; la cita en p. 1052.

12

Es decir, a El Cuento Semanal (1907-1912), que dirigió Eduardo Zamacois; La novela corta (1916-1925), dirigida por José de Urquía; La Novela Semanal (1921-1925), publicada por Prensa Gráfica; La Novela de hoy (1922-1932) dirigida por Artemio Precioso o La Novela Mundial (1926-1928), con José García Mercadal por director; etc. etc. El CSIC tiene en marcha un proceso de catalogización de la «Literatura breve» española de la primera mitad del siglo XX, bajo la dirección de Alberto Sánchez Álvarez-Insúa; v. de este autor Las Colecciones Literarias en el Madrid de Alfonso XIII, Madrid, 1997. Ayuntamiento de Madrid/Instituto de Estudios Madrileños, (Ci- a escribir bailables o diversiones», escribe Neruda en el prólogo citado, y ello ha sido interpretado, no como un rechazo a la narrativa en general sino como un rechazo «a la narrativa de preocupación americanista vigente en esos años»?. No estoy seguro. Es cierto que al título de muchas de las novelas publicadas en los años en que apareció $E l$ babitante... podría haberse agregado el subtítulo de «novela de costumbres chilenas», pero también es cierto que muchas otras hubieran soportado difícilmente ese agregado (p.ej. Medianoche, de Ángel Cruchaga Santa María; p. ej. El cazador de tiburones, de Salvador Reyes; p.ej. La tragedia del arte, de Nathanael Yáñez Silva, por citar sólo tres de las novelas publicadas en $\left.1926^{10}\right)$. Puede que «bailables y diversiones» tuviera, para el poeta chileno, otro significado. Él mismo, en una entrevista coetánea a la aparición de $E l$ habitante..., había propuesto una explicación de ese prólogo, que -decía- había sido escrito contra los poetas que creían hacer «arte nuevo» por cantar cosas de reciente novedad, contra los que fingen escribir "por pura diversión», contra los que menosprecian a los bohemios...

Por eso -agrega-, como una reacción contra esta moda estúpida, escribí mi prólogo de El babitante y su esperanza. A mí me cuesta escribir; yo creo que el arte es una cosa seria; no tengo vergüenza de decir que soy escritor, y prefiero a los hombres insatisfechos, aun cuando se hallen entre los criminales... ${ }^{11}$

Esa confusa explicación que entremezcla a futuristas, sablistas y gente seria, quizás encierra parte de la verdad, pero no toda la verdad. Hacia 1920 (años antes, años después) se publican en diversos países de América colecciones de novelas cortas, cuyas características editoriales eran semejantes a las de las colecciones homólogas españolas de aquella época (escaso número de páginas, grandes tiradas, precio reducido) ${ }^{12}$. Así sucede en Argentina con La novela semanal (1917-1926), creada por el editor español Miguel Sans, y otras muchas colecciones (El cuento ilustrado, 1918; La novela de hoy, 1918; La novela del día, 19181924; La novela para todos, 1918-1919; La novela de la juventud, 1920-1922; La novela nacional, 1920-1922; La novela universitaria, 1921-1922); La novela porteña, 1922-1923; La mejor novela, 1928-192913) de las cuales, en 
1923, circulaban semanalmente medio millón de ejemplares; en Colombia con La novela semanal (1923-1925), fundada por Luis Enrique Osorio (cuyo primer número incluía la novela de Emilio Cuervo Márquez, Lilí $\left.{ }^{14}\right)$; en Perú con La novela peruana (inaugurada en 1923 con Mors ex vita, de Clemente Palma); en Venezuela con La novela semanal, fundada en 1922 por José Rafael Pocaterra y Rómulo Gallegos. Y en Chile con Lecturas Selectas (dedicada no sólo a la novela) que dirigieron Luis Enrique Délano y Amanda Labarca; con Las novelas cortas y La novela nueva (colecciones estas últimas de que sólo tengo datos fragmentarios); sin contar la tardía Narraciones Zig-Zag, creada en 1933. Nascimento mismo parece haber querido instaurar su propia colección de novelas cortas, según se puede seguir de la aparición, entre el 26 y el 28 de varias obras de extensión similar a El habitante y su esperanza en ese sello editorial.

Más allá de los dicterios que la literatura de algunas de estas colecciones mereció en su época («literatura barata», «literatura industrial», literatura «pornográfica, ñoña, cursi»), en general justificados, es indiscutible que tales colecciones surgieron como respuesta a una situación en que nuevas condiciones sociales favorecían la incorporación de nuevos sectores de la población a la lectura. Para aprovechar la existencia de ese nuevo público lector, de recursos limitados, se crearon probablemente las colecciones literarias mencionadas. El rechazo provocado por ellas en algunos círculos intelectuales era, en muchos casos, producto del elitismo.

El prólogo del joven Neruda parece responder a esa posición ${ }^{15}$, que se matiza en otra de sus frases:

Como ciudadano, soy hombre tranquilo, enemigo de leyes, gobiernos e instituciones establecidas. Tengo repulsión por el burgués, y me gusta la vida de la gente intranquila e insatisfecha, sean éstos artistas o criminales.

Tal declaración no hace sino explicitar un sentimiento cuya vigencia excede, hacia atrás y hacia delante, los años veinte del siglo pasado y traspasa las fronteras chilenas y americanas: la auto comprensión de escritores y artistas en la sociedad burguesa, hecha de atracción y de rechazo.

Jaime Concha, siempre brillante, ha ilustrado los rasgos de ese sentimiento, describiendo la situación del joven Neruda en el exacto año en que escribe El habitante y su esperanza:

Ha dejado de ser estudiante, no ha llegado a ser profesor. Su actividad, la de escribir, es un penoso entusiasmo que no le aporta rentas periódicas ni lo somete, día tras día, a un horario fijo de obligaciones. No es un oficio ni es un trabajo; ni siquiera una clase de cesantía. Es, a lo sumo, un ocio inaceptable que estatuye el extrañamiento social del poeta. He aquí la primera antinomia de su experiencia: en cada momento vive su libertad, en cada momento respira su esclavitud. Libre, distribuye el tiempo a su capricho; esclavo, depende para todo del tiempo social de que está excluido ${ }^{16}$.

$$
* * *
$$

Ahora bien, el «extrañamiento social» distingue no solamente al ciudadano Neruda, al poeta Neruda, sino también al narrador y protagonista de El habitante y su esperanza y esto ocurre premeditadamente. La locución conjuntiva «Ahora bien» (i.e., «Esto supuesto o sentado», para reproducir la definición del DRAE) con que comienza el texto de la novela no puede interpretarse como una de las anomalías sintácticas de Neruda analizadas por Amado Alon$\mathrm{so}^{17}$, sino como nexo entre el prólogo de la obra (y específicamente, entre la última frase de éste) y el texto de ella; como si no existiera entre ambos solución de continuidad:

Como ciudadano, soy hombre tranquilo, enemigo de leyes, gobiernos e instituciones establecidas. Tengo repulsión por el burgués, y me gusta la vida de la gente intranquila e insatisfecha, sean éstos artistas o criminales... Ahora bien, mi casa es la última de Cantalao, y está frente al mar estrepitoso, encajonada contra los cerros [etc., etc.] ${ }^{18}$.

De esta manera el narrador de El habitante y su esperanza aparece revestido con las características que el prólogo asigna a la figura que

14

Vid., Jimena Montaña Cuéllar, "La novela semanal de Luis Enrique Osorio», Boletín Cultural y Bibliográfico, no 35, vol. XXXI, Caracas, Banco de la República, 1994, [1995].
15

Esto es, más a «la distinción entre alta y baja cultura», que $a$ «la asunción personal de una visión democrático-revolucionaria del mundo y de la historia»; las dos frases entrecomi-

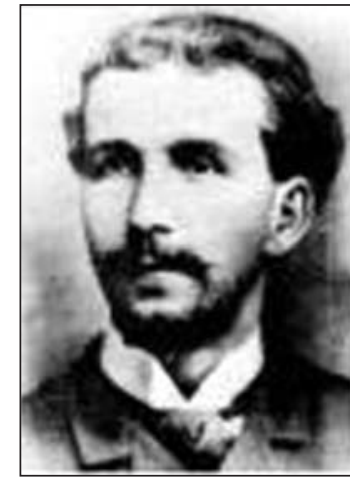

José Asunción Silva.

lladas pertenecen a Hernán Loyola, Pablo Neruda, Obras completas, ed. cit., I, pág. 1164.

16

Jaime Concha, Neruda (19041936), Santiago de Chile, Universitaria, 1972, p. 219.

17

Neruda utiliza la misma locución en dos poemas de la primera $R e$ sidencia, en ambas ocasiones con su valor de conexiva: "Ahora bien, de qué está hecho ese surgir de palomas / que hay entre la noche y el tiempo» ("Galope muerto»); "Ahora bien, en lo largo y largo, / de olvido a olvido residen conmigo» ("Madrigal escrito en invierno»). Reparemos en que ambos poemas son coetáneos de El habitante...: "Galope muerto» fue escrito, según Hernán Loyola, «en los primeros meses de 1926», en tanto "Madrigal escrito en invierno» es anterior, pues su primera versión es de 1925 .

18

Es cierto que entre esas dos frases está el nombre del poeta; y en la edición princeps y en algunas otras, «Prólogo» y novela están claramente diferenciados, no sólo por el tipo de letra, sino porque el título de El habitante y su esperanza está después del «Prólogo» y su firma y antes del texto de la obra, pero esas peculiaridades tipográficas lejos de disipar, refuerzan, en algún sentido, la continuidad entre prólogo y texto.

\footnotetext{
El habitante y su esperanz

y la novela de su época

LUIS ÍÑIGO-MADRIGAL
} 


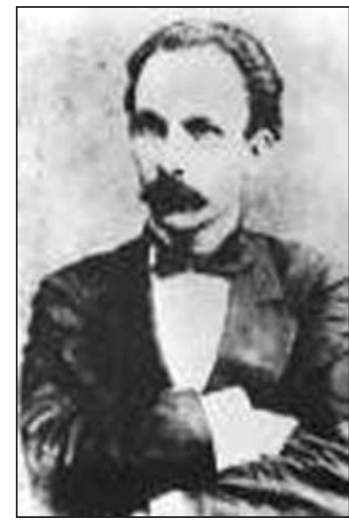

José Martí.

19

Dolores Phillipps-López, La novela hispanoamericana del modernismo, Genève, Editions Slatkine, 1996, pág. 174.

\section{0}

José Asunción Silva, De sobremesa, Bogotá, Cromos, 1925.

21

Hernán Loyola supone que José Silva hace referencia a Álvaro Hinojosa, (amigo de Neruda y compañero suyo en su primer viaje a Oriente), basándose en el "pseudónimo» de Hinojosa, Álvaro de Silva; pero ese pseudónimo -o quizás nombre legal-es posterior a El habitante y su esperanza. Así lo muestra el retrato de Hinojosa hecho por Neruda en Confieso que he vivido (texto invocado por Loyola), y otras muchas fuentes, entre ellas el libro de memorias de Homero Arce, Los Libros y Los Viajes, Recuerdos de Pablo Neruda, Editorial Nascimento, 1980, en cuyo prólogo la viuda de Arce, Laura Arrué escribe: «Conocí personalmente a Homero Arce Cabrera en el año 1928. Antes sabía de él por referencias de sus amigos, principalmente de Pablo, además de Rubén Azócar, Orlando Oyarzún, Álvaro Hinojosa (hoy Álvaro de Silva) ...».

\section{2}

Las líneas anteriores resumen uno de los apartados del ya citado libro de Dolores Phillipps-López, La novela hispanoamericana del modernismo, Genève, Editions Slatkine, 1996.

23

Pedro Prado, Alsino, Santiago de Chile, Minerva, 1920.

El habitante y su esperanza y la novela de su época

LUIS ÍNIIGO-MADRIGAL lo firma. Artista y criminal a la vez, este personaje bifronte convierte la obra, sesgadamente, en una especie de «novela de artista». Este subgénero, como se sabe, nació en la Alemania romántica, y en él la figura del narrador-artista «encarna al individuo en objeto central del mundo novelado [lo que explica] la generalizada adopción de la perspectiva singular».

La novela de artistas constituirá el marco narrativo en que más explícitamente se condense y manifieste el desasosiego que caracterizó la relación conflictiva y ambigua del artista con la sociedad burguesa moderna, ${ }^{19}$

y por ello el subgénero atraviesa un largo período de la historia de la literatura, desde el romanticismo en adelante.

En nuestra América la más famosa novela de artistas es, sin duda, De sobremesa, del poeta modernista colombiano José Asunción Silva (1865-1896), publicada póstumamente en $1925^{20}$, aunque de ella hubieran aparecido con anterioridad numerosos fragmentos en periódicos y revistas. La obra reviste la forma de Diario de un viaje a Europa del desmesurado y psicótico millonario hispanoamericano José Fernández, que éste lee a sus amigos ya de vuelta a su patria.

Es poco probable que Neruda conociese la obra de Silva (por más que ésta tuviera una segunda edición en el mismo año de 1925 y que el chileno mostrase en varias ocasiones su admiración por el colombiano), pero entre las dos novelas hay al menos un sorprendente punto de contacto: el protagonista y narrador de De sobremesa se llama José Fernández (exagerado alter ego del propio José Asunción SiLva) y un personaje de la obra, amigo poco querido a quién José Fernández pone los cuernos en uno de los episodios más significativos de la obra, Paco RIVAs; en El habitante y su esperanza el narrador protagonista se llama José SILVA y su antagonista Florencio RIVAS $^{21}$.

$* * *$

Ahora bien, la novela de Neruda es sólo sesgadamente una «novela de artista»; es, cumplidamente, una novela artística, una novela lírica, poemática.

El poeta francés Jean Moréas en un artículo publicado en el suplemento literario del $\mathrm{Fi}^{-}$ garo del 18 de septiembre de 1886 abogó por una novela fundada en la visión subjetiva de lo real, cuyo interés estuviera centrado en alguna aventura interior, enmarcada en un decorado o escenario que, más que descrito, quedara sugerido. El programa de Moréas no dio ocasión a obras memorables, pero muestra la poligénesis de un proyecto que, en nuestra América, produciría varias «novelas poemáticas» entre los modernistas, y cuyo esquema puede reconocerse también en algunas novelas de «vanguardia» ${ }^{22}$.

Entre las primeras conviene no olvidar la obra del chileno Pedro Prado (1886-1952) Alsino, publicada en 1920, a la que su autor llamó «poema novelesco» ${ }^{23}$. Neruda sostuvo una constante amistad con Prado y, en una carta que le dirige en enero de 1923, escribe:

Estoy ya, desde hace tiempo, en Temuco. Llueve, llueve. Debiera haberle escrito antes pero me da vergüenza no poder decirle casi nada de Alsino, que acabo de leer. Por qué diablos me pasa esto? Me gusta extrañamente, volveré a leerlo en estos días, y no sé decir qué es lo que me gusta. Sin embargo creo ser un lector inteligente. Debe ser el temor a decir vulgaridades o algo parecido. Además de los cantos del $\mathrm{Al}$ sino, me parecen incomparablemente bellos los capítulos «Una mañana de primavera» $\mathrm{y}$ «En el verano silencioso».

La novela de Pedro Prado tiene un marco escénico campestre, y las descripciones de la naturaleza -que guardan semejanza con las de El habitante y su esperanza- ocupan en ella un lugar importante; pero tiene también una serie de otras características que formarían parte de la llamada «novela mundonovista». Esas características fueron enumeradas por Francisco Contreras (escritor chileno que fue el primero en emplear el vocablo «mundonovismo» para denominar las nuevas formas del criollismo hispanoamericano), en el prólogo de su novela El pueblo maravilloso, que apareció en francés en 1924 y que, en versión española, vio la luz en 1927. Allí Contreras sostiene la identidad esencial de todos los países de América española, manifestada en la comunidad de costumbres, tradiciones y en la «intuición muy despierta de lo maravilloso» y propugna, para expresarlas una «Novela Integral y Lírica» que, al interpretar al hombre, no olvide «los fenómenos de la subconciencia o de lo inconsciente» y 
abandone «la veleidad de las pretendidas lenguas regionales» ${ }^{24}$.

Alsino prefiguraba el desideratum de Francisco Contreras, aunque éste quizá no la hubiera leído. El habitante y su esperanza se inscribía, también, en ese proyecto, si bien lo volcaba en una llamativa prosa vanguardista.

$$
* * *
$$

Podría decirse que la prosa vanguardista es aquella que opta, preferentemente, por los recursos de la alienación. Para la antigua retórica el discurso puede moverse entre un grado máximo de claridad y un grado máximo de obscuridad. El vicio de la claridad consiste en que, extremada, provoca el aburrimiento; los recursos de la alienación son los destinados a evitar el aburrimiento, y se pueden aplicar a res y verba; pero su abuso provoca la ininteligibilidad. En el relato vanguardista los recursos de la alienación se manifiestan en la inventio, la dispositio y la elocutio del discurso; alcanzan a los acontecimientos, a los espacios, a los personajes de la novela; tiñen la ortografía y la tipografía del texto impreso.

Buena muestra de ello es el que algunos tienen por primer relato vanguardista hispanoamericano: La señorita etcétera, del mexicano Arqueles Vela, cofundador y representante del «estridentismo», aparecido en 1922. Esa breve narración, según su autor en entrevista con Roberto Bolaño,

...fue la primera novela que viola la estructura tradicional en nuestras latitudes hispanoamericanas... [en ella se] viola los conceptos de tiempo y de espacio y [se] elimina los personajes [pues es] una novela en donde el Yo es el determinante, y es el Yo, lo subjetivo, lo que convierte en personajes a los transeúntes, a la idea que se tiene acerca del hombre, de la mujer [e] inclusive al paisaje [por lo que se la denonima] novela poética ${ }^{25}$,

\section{En La señorita etcétera encontramos todos} los recursos de la alienación que se encuentran en El habitante y su esperanza, pero (como la novela de Neruda) hay en ella elementos que remiten al resto de las formas novelescas vigentes en las primeras décadas del siglo XX, en Hispanoamérica ${ }^{26}$.

Elitismo; rechazo de la sociedad burguesa y extrañamiento social; encarnación del individuo como objeto central del mundo novelado; difuminación de los límites entre lírica y épica; nueva visión del «nacionalismo» literario; recursos destinados a provocar la alienación... Todos esos rasgos -cuya fuente prime$\mathrm{ra}$, en la literatura hispanoamericana, acaso haya que buscar en «esa gran libertad que se llamó modernismo»- coexisten en la novela hispanoamericana de las primeras décadas del siglo pasado, y pueden encontrarse (o suponer que se encuentran) en obras anteriores a $E l$ babitante y su esperanza.

Pues la literatura es como un caleidoscopio, en el que unos pocos elementos -al reflejarse en el doble espejos de los poetas y de la lengua- se combinan y forman figuras de apariencia muy diversa. Pero los lentos dedos de la Historia giran el caleidoscopio lentamente, y los colores y formas que ahora vemos recuerdan las que hemos visto hace un instante y anuncian las que vendrán en seguida.

\section{Las Matas - Alicante, abril del 2004}

24

Francisco Contreras, La Ville Merveilleuse, Paris, Renaissance du Livre, 1924; ID. El pueblo maravilloso. Novela, Paris, Agencia Mundial de Librería, 1927, 272 pp.; cito por el «Proemio» de esta última edición, passim.

25

Roberto Bolaños, «Arqueles Vela», La Palabra y el Hombre, Universidad Veracruzana, octubre-diciembre 1981, pp. 8589.

\section{6}

Se ha indicado, también, la influencia de algunas obras nohispánicas sobre El habitante y su esperanza. Señaladamente la de de Mon frère Yves, de Pierre Loti (Hernán Loyola en su edición de las Obras completas, de Neruda, ya citada: I, pág. 1164); de Los cuadernos de Malte Laure Brigge, de Rainer María Rilke (Hernán Loyola, «El habitante y su esperan$z a$, relato de vanguardia», Actas del Simposio Internacional de Estudios Hispanicos, Akademiai Klado, Budapest,
1976; reprod. en Cuadernos para Investigación de la Literatura Hispánica, 2-3 (Madrid, 1980): 213-222); y de El Océano de Leonidas Andreiev (Volodia Teitelboim, El corazón escrito. Una lectura latinoamericana de la literatura rusa y soviética, Moscú, Ráduga, 1986); como es natural tales influencias no pueden desecharse sin más, pero a mi juicio, de existir, no bastan a ex plicar la obra del chileno. Mon frère Yves, de Pierre Loti (Paris, Calmann Lévy, 1883; $1^{\underline{9}}$ trad española : Mi hermano Yves, traducción de Antolín San Pedro, Madrid, Imprenta de Enrique Rubiños, 1888); como indica Loyola (loc. cit.) el El habitante y su esperanza tiene en el capítulo XIV un epígrafe de esa obra, en español $-\ll P e-$ ro, por desgracia, habíase metido entonces en un mal negocio»-, extremadamente general (tanto como para que me sea imposible encontrar de qué lugar de la obra de Loti proviene), que marca en todo caso una diferencia fundamental entre las dos novelas: Mon frère Yves está narrada en ter-

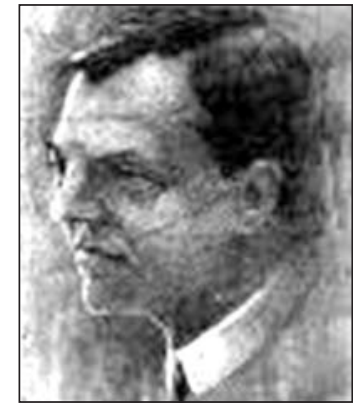

Pedro Prado, 1921

cera persona, como su título lo indica, mientras que El habitante y su esperanza lo está en primera; aparte de eso, pocos elementos comunes hay entre las dos. En cuanto a Los cuadernos de Malte Laurids Brigge, de Rilke (Die Aufzeichnungen des Malte Laurids Brigge) que fueron publicados en su lengua original en 1910, se sabe que Neruda, tradujo del francés fragmentos de la obra y los publicó en la revista Claridad, de la Federación de Estudiantes ( $n^{\circ}$ 135, 1926); pero la primera traducción francesa (Les Cahiers de Malte Laure Brigge, traducción de Maurice Betz, Paris, Stock, 1923, 122 pp.), sólo comprende alrededor de un cuarto del original, cuya versión completa aparecería en francés en el año 1926, sin tiempo para influir en El habitante y su esperanza, que fue escrita entre 1925 y comienzos de mismo 1926; sin embargo es indiscutible que entre esa obra de Rilke y la novela de Neruda se puede establecer algunas similitudes. Finalmente, en cuanto a Andreiev, no se puede discutir la admiración que Neruda sintió por el escritor ruso (sobre todo por su novela Sachka Yegulev, título que llegó a utilizar como pseudónimo), testimoniada en múltiples ocasiones por el poeta chileno; pero El Océano (que en su versión original es un drama en siete cuadros, estrenado en 1911 y que Neruda podría haber leído en español, como novela (Leonidas Andreiev, traducción de A. Ruste, Madrid, Variorum, 1921, 223 pags.), tiene poco que ver -por su argumento y por su estilo- con El habitante y su esperanza.

El habitante y su esperanza

y la novela de su época

LUIS ÍÑIGO-MADRIGAL 